$$
\text { DOE/MT/95011-TT2 }
$$

\title{
Scale-Up of Advanced Hot-Gas Desulfurization Sorbents
}

Type of Report:

Reporting Period

Principal Investigators

Date:

DOE Award Number:

Name and Address:

DOE Project Officer
Technical Progress Report, Report Number: 3

April 1, 1996- September 30, 1996

K. Jothimurugesan

Santosh K. Gangwal (RTI)

October 14,1996

DE-FG22-95MT95011

Hampton University

Department of Chemical Engineering

Hampton, Virginia 23668

Kamalendu Das

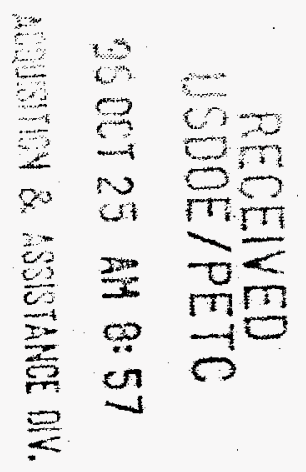

GSTRIBUTION OF THIS DOCUMENT IS UNUMTEO H 


\section{DISCLAIMER}

Portions of this document may be illegible in electronic image products. Images are produced from the best available original document. 


\section{DISCLAIMER}

This report was prepared as an account of work sponsored by an agency of the United States Government. Neither the United States Government nor any agency thereof, nor any of their employees, makes any warranty, express or implied, or assumes any legal liability or responsibility for the accuracy, completeness, or usefulness of any information, apparatus, product, or process disclosed, or represents that its use would not infringe privately owned rights. Reference herein to any specific commercial product, process, or service by trade name, trademark, manufacturer, or otherwise does not necessarily constitute or imply its endorsement, recommendation, or favoring by the United States Government or any agency thereof. The views and opinions of authors expresses herein do not necessarily state or reflect those of the United States Government or any agency thereof. 


\begin{abstract}
The overall objective of this project is to develop regenerable sorbents for hot gas desulfurization in IGCC systems. The specific objective of the project is to develop durable advanced sorbents that demonstrate a strong resistance to attrition and chemical deactivation, and high activity at temperatures as low as $343^{\circ} \mathrm{C}\left(650^{\circ} \mathrm{F}\right)$. A number of formulations will be prepared and screened in a 1/2-inch fixed bed reactor at high pressure (1 to $20 \mathrm{~atm}$ ) and high temperatures using simulated coal-derived fuel-gases. Screening criteria will include, chemical reactivity, stability, and regenerability over the temperature range of $343^{\circ} \mathrm{C}$ to $650^{\circ} \mathrm{C}$. After initial screening, at least 3 promising formulations will be tested for 25-30 cycles of absorption and regeneration. One of the superior formulations with the best cyclic performance will be selected for investigating scale up parameters. The scaled-up formulation will be tested for long term durability and chemical reactivity.
\end{abstract}




\section{TABLE OF CONTENTS}

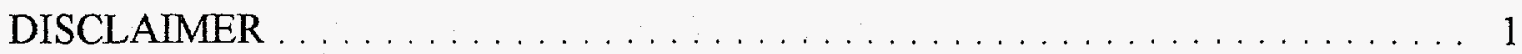

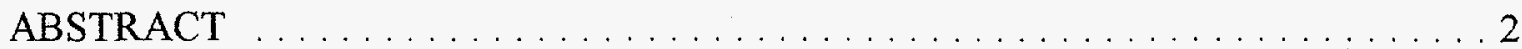

TABLE OF CONTENTS ........................ 3

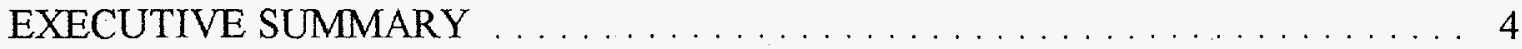

INTRODUCTION ........................... 4

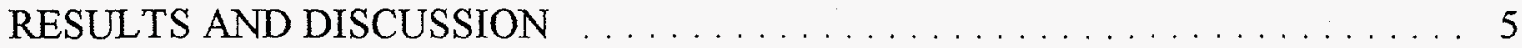

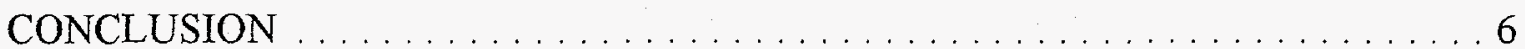

PUBLICATION/PRESENTATION ................... 6 


\section{EXECUTIVE SUMMARY}

Additional sorbents were prepared and then tested for its hydrogen sulfide removal efficiency. Based on the results of the extensive testing conducted on this project so for, the zinc oxide-based sorbent is the best sorbent for hot has application in the temperature range of $343^{\circ} \mathrm{C}$ to $538^{\circ} \mathrm{C}$.

\section{INTRODUCTION}

Advanced high-efficiency integrated gasification combined cycle (IGCC) power systems are being developed to produce power from coal under the U.S. Department of Energy's (DOE's) multibillion dollar Clean Coal Technology (CCT) Program. In these advanced systems, coal is gasified to produce a gas at high temperature and high pressure (HTHP) conditions. The hot gas is cleaned of contaminants, primarily particulates and sulfur gases such as hydrogen sulfide $\left(\mathrm{H}_{2} \mathrm{~S}\right)$ and burned in a combustion turbine. IGCC systems are capable of higher thermal efficiency and lower gaseous, liquid, and solid discharges than conventional pulverized-coal-fired power plants. Hot gas cleanup offers the potentially key advantages of higher plant thermal efficiencies and lower costs due to the elimination of fuel gas cooling and associated heat exchangers

Sorbents based on zinc oxide are currently the leading candidates and are being developed for moving-, and fluidized-bed reactor applications. Zinc oxide based sorbents can effectively reduce the $\mathrm{H}_{2} \mathrm{~S}$ in coal gas to $10 \mathrm{ppm}$ levels and can be regenerated for multicycle operation. However, all of the current first-generation leading sorbents undergo significant loss of reactivity with cycling, as much as $50 \%$ or greater loss in only $25-30$ cycles. Stability of the hot-gas desulfurization step over 100s of cycles is essential for improved IGCC economics over conventional power plants. Thus a pressing need exists for developing durable second generation sorbents with much improved and stable reactivity during cyclic operation.

The overall objective of this project is to develop regenerable sorbents for hot gas desulfurization in IGCC systems. The specific objective of the project is to develop durable advanced sorbents that demonstrate a strong resistance to attrition and chemical deactivation, and high activity at temperatures as low as $343^{\circ} \mathrm{C}\left(650^{\circ} \mathrm{F}\right)$. 


\section{RESULTS AND DISCUSSIONS}

The project consists of three major experimental tasks (Tasks 1-3) addressing the contract objectives described above.

Task 1: Optimization of Preparation

Task 2: Investigation of Scale-Up

Task 3: Preparation of $100 \mathrm{lb}$ Batch

\section{Task 1: Optimization of Preparation}

A highly promising method was recently developed to prepare suitable sorbents. Various sorbents were prepared by our proprietary method. The main parameters we have varied was various concentrations of starting materials and ageing conditions. The starting compounds was chosen based on water solubility, commercial availability and low costs and that avoid introducing elements that may be deleterious in the final sorbent or that cause difficulties in subsequent processing. These prepared sorbents were tested in the fixed bed reactor.

The following analytical techniques was used to characterize the fresh, sulfided and regenerated sorbents

1. X-ray Diffraction (XRD) for crystalline phase.

2. Surface area measurement will be based on the standard BET method.

3. Hg-porosimetry for pore volume, bulk density, average pore diameter and pore size distribution determination.

4. Atomic Absorption (AA) Spectrometry for elemental composition analysis.

\section{Task 2. Investigation of Scale-Up}

Forming operations to making particles for both fluidized-bed and moving bed was investigated by a balance among several factors, including rheological properties of the mixture, and the necessity to achieve satisfactory strength, an open-pore structure, and high activity for hydrogen sulfide removal. Suitable rheological properties was obtained by incorporating certain organic (e.g. methocel) and inorganic binders (e.g. kaolin and bentonite) and micropore formers.

The $\mathrm{ZnO}$-based sorbentsMCRH-41, 42, 43, 44, 45, 46, 47, 49, were evaluated in a sulfidation gas mixture containing (in vol\%): $\mathrm{H}_{2}=10 \%, \mathrm{CO}=15 \%, \mathrm{CO}_{2}=5 \%, \mathrm{H}_{2} \mathrm{~S}=1.0 \%$, 
$\mathrm{H}_{2} \mathrm{O}=15 \%$ and bal $\mathrm{N}_{2}$. Figures 1-9 show the $\mathrm{H}_{2} \mathrm{~S}$ breakthrough profiles as a function of time. Of the sorbents tested MCRH-42 (Fig2.) showed excellent sulfidation behaviour. The prebreakthrough $\mathrm{H}_{2} \mathrm{~S}$ level was less than $100 \mathrm{ppm}$ and the breakthrough conversion was $100 \%$. Regeneration of this sorbent was conducted with 2 volume percent $\mathrm{O}_{2}$ in $\mathrm{N}_{2}$ at $550^{\circ} \mathrm{C}$.

\section{CONCLUSION}

Based on the results of the extensive testing conducted on this project so for, the zinc oxide-based sorbent is the best sorbent for hot has application in the temperature range of $343^{\circ} \mathrm{C}$ to $538^{\circ} \mathrm{C}$.

\section{FUTURE WORK}

The future activity will include, development and testing of attrition resistance zinc oxide based sorbents for fludized bed applications.

TIME SCHEDULE FOR YEAR 2

\begin{tabular}{|l|c|c|}
\hline \multicolumn{1}{|c|}{ TASK } & \multicolumn{2}{c|}{ Semiannual } \\
\cline { 2 - 3 } & 1 & 2 \\
\hline Sorbent Preparation & \\
\hline Sorbent Characterization & \\
\hline Sorbent Evaluation & \\
\hline Investigation of Scale-Up & & \\
\hline Final Report & & \\
\hline Semiannual Reports & & \\
\hline
\end{tabular}

\section{PUBLICATION/PRESENTATION}

1. K. Jothimurugesan, A.A. Adeyiga and S.K. Gangwal "Regenerable Sorbents for Desulfurization of Coal Gas", Fourth Annual HBCUs/Private Sector Energy 
Research and Development Technology Transfer symposium, Greensboro, NC, April 2-4, 1996.

2. K. Jothimurugesan, A.A. Adeyiga and S.K. Gangwal, "Removal of Hydrogen Sulfide from Hot Coal Gas Streams", Thirteenth Annual International Pittsburgh Coal Conference Proceedings, p.596-601, 1996. 


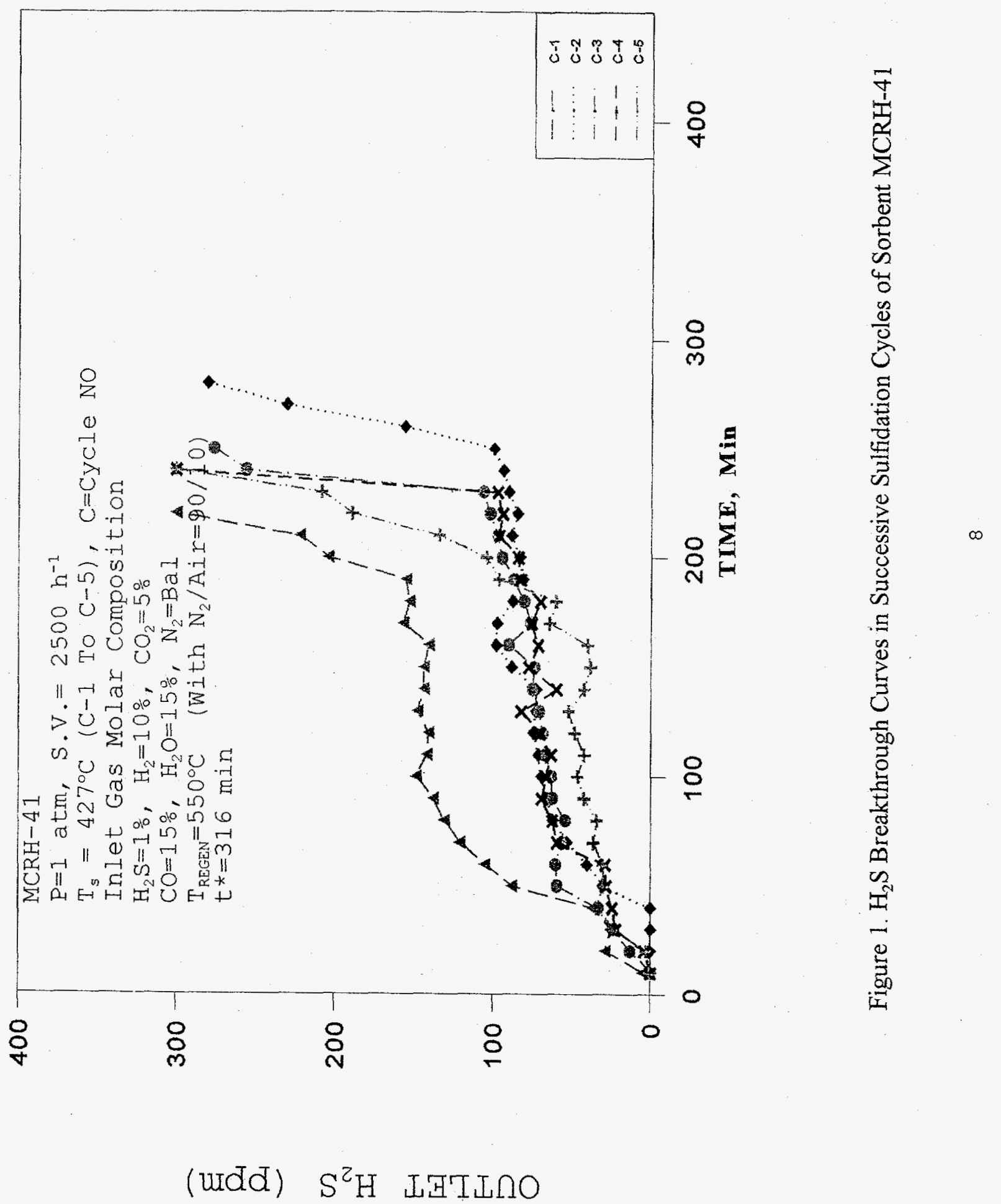




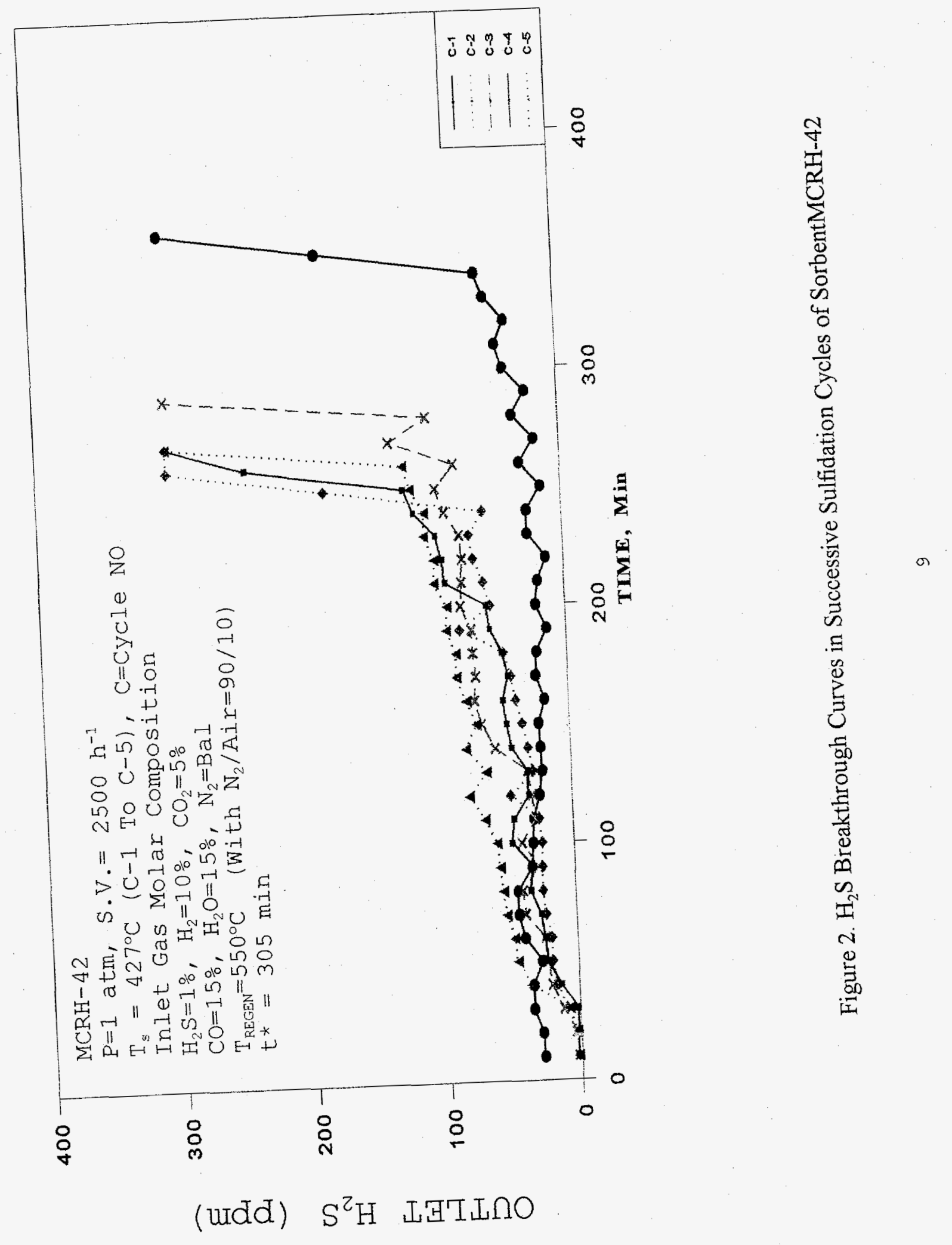




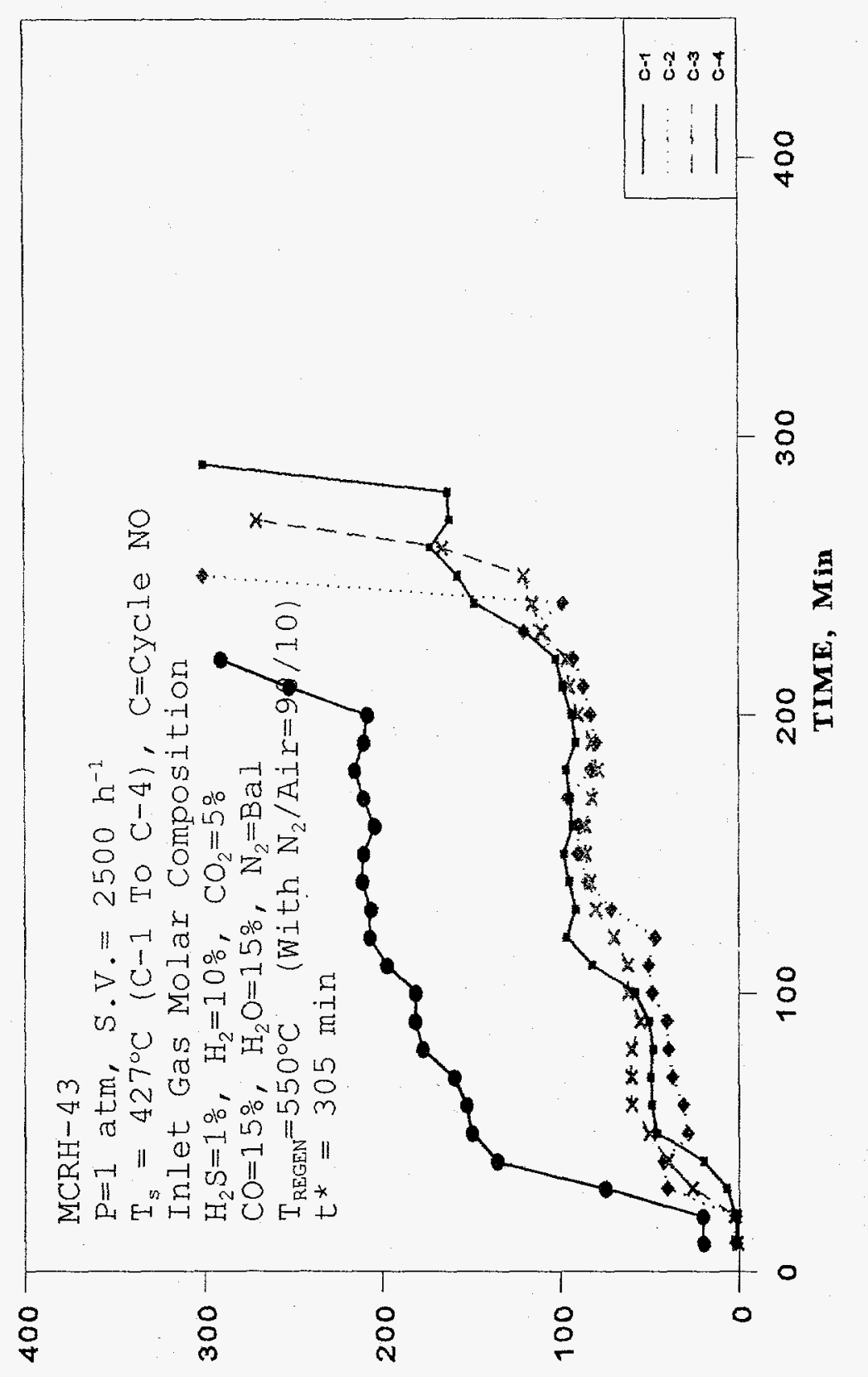

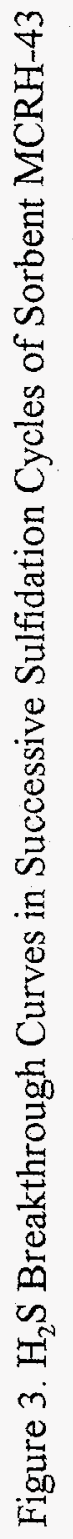

(udd) $\mathrm{S}^{2} \mathrm{H}$ 山rTunO 


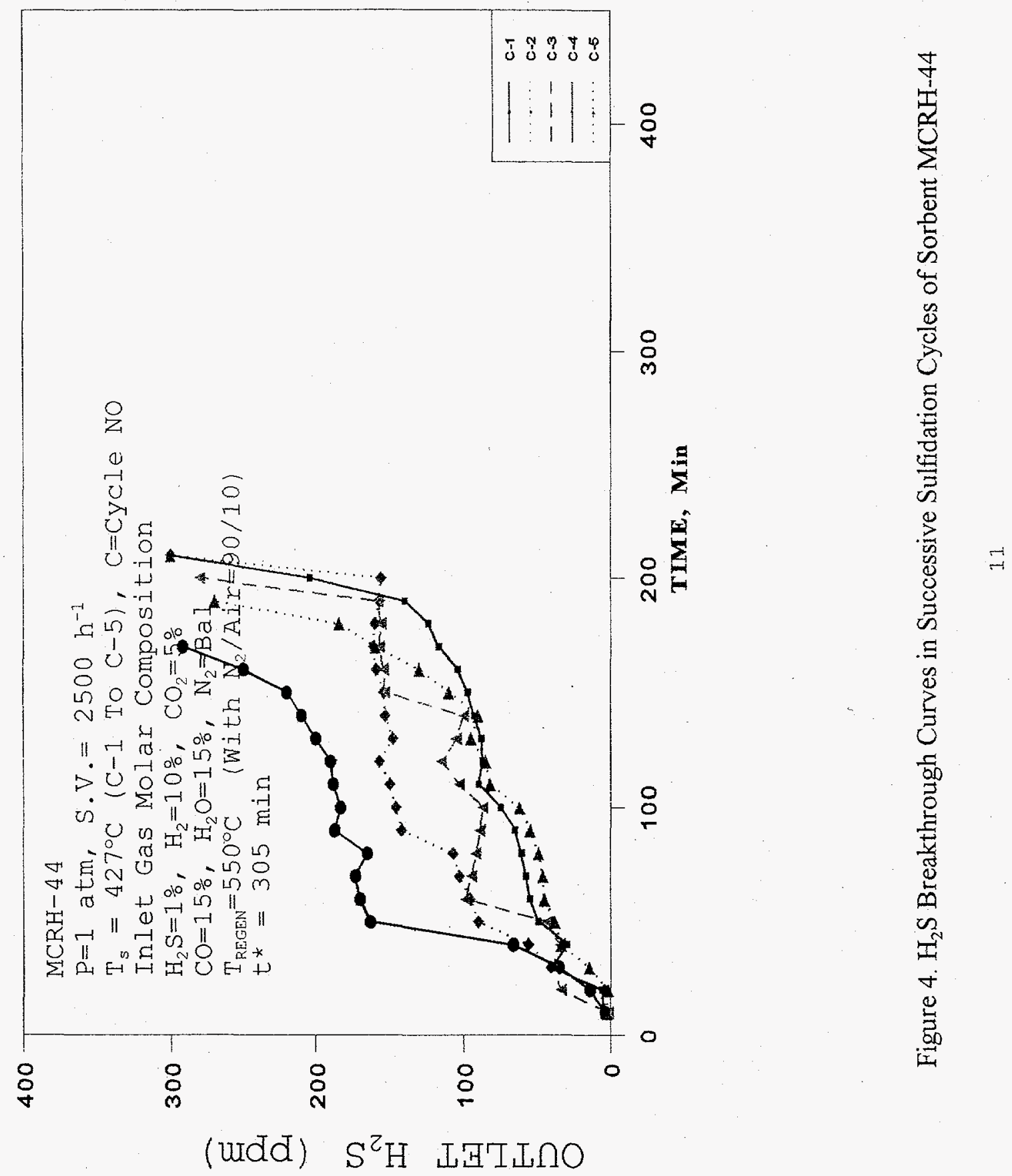




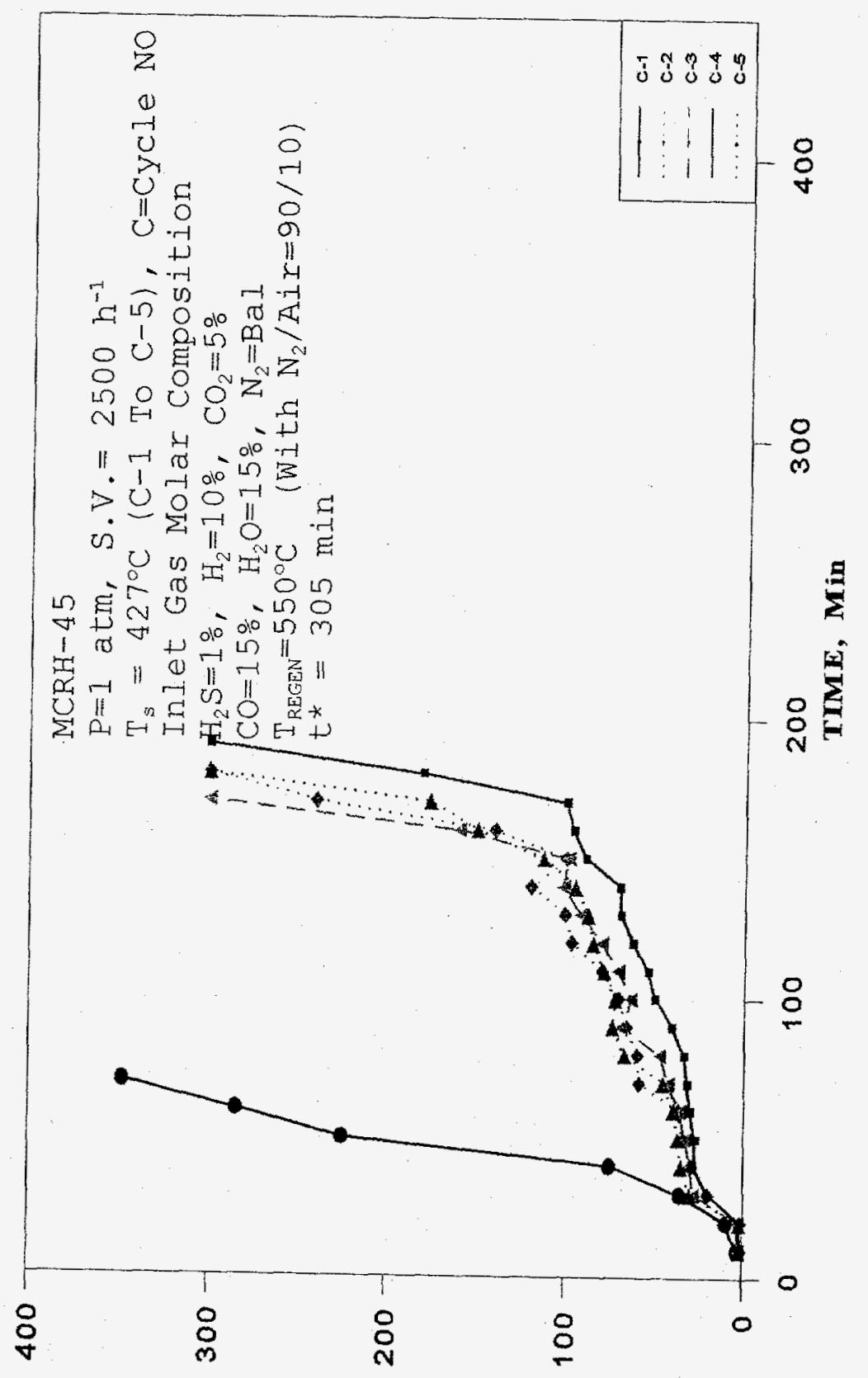

$n$
1
1
0
0
0
0
0
0
0
0
2
4
0
0
0
0
0

N

$11-4$, $100-7$

. 1 , alo in 3

$>U$ OO

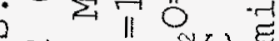

0 的证。

हin -10

1 ति $\nabla$ 이 인

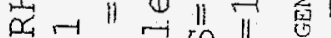

If nद 0 置

5

(udd) $S^{2} \mathrm{H}$ 山'HTLดO 


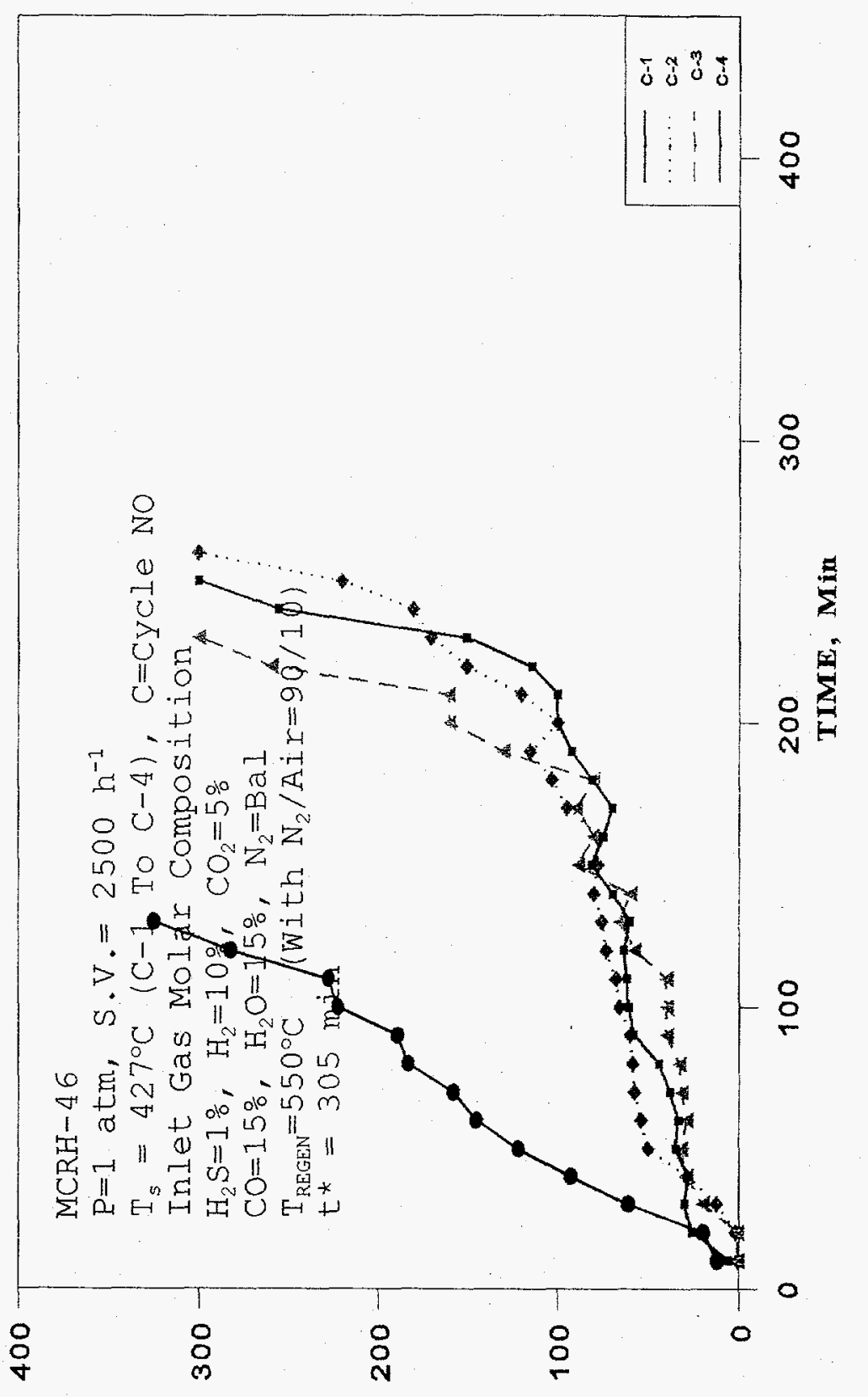

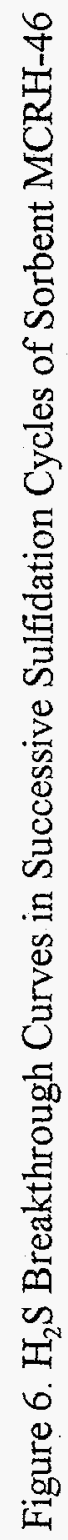

(urdd) $S^{2} \mathrm{H}$ 山'HT山กO 


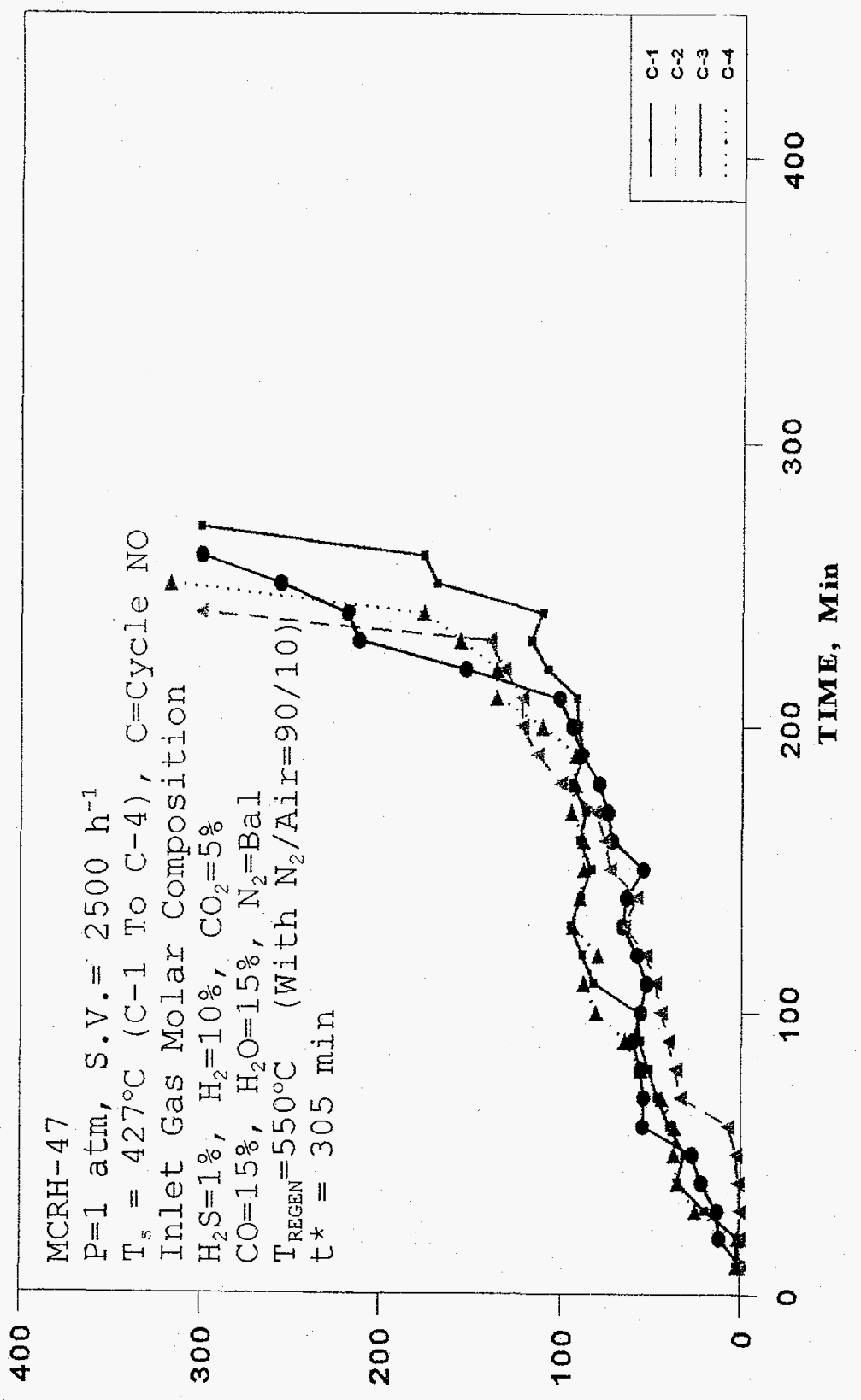

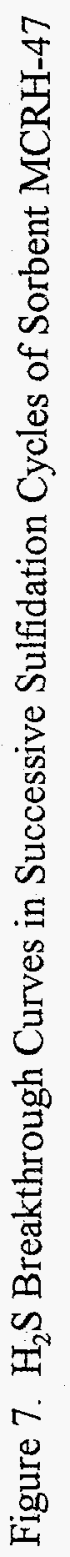

(udd) $\mathrm{S}^{2} \mathrm{H}$ 山'HT山ดO 


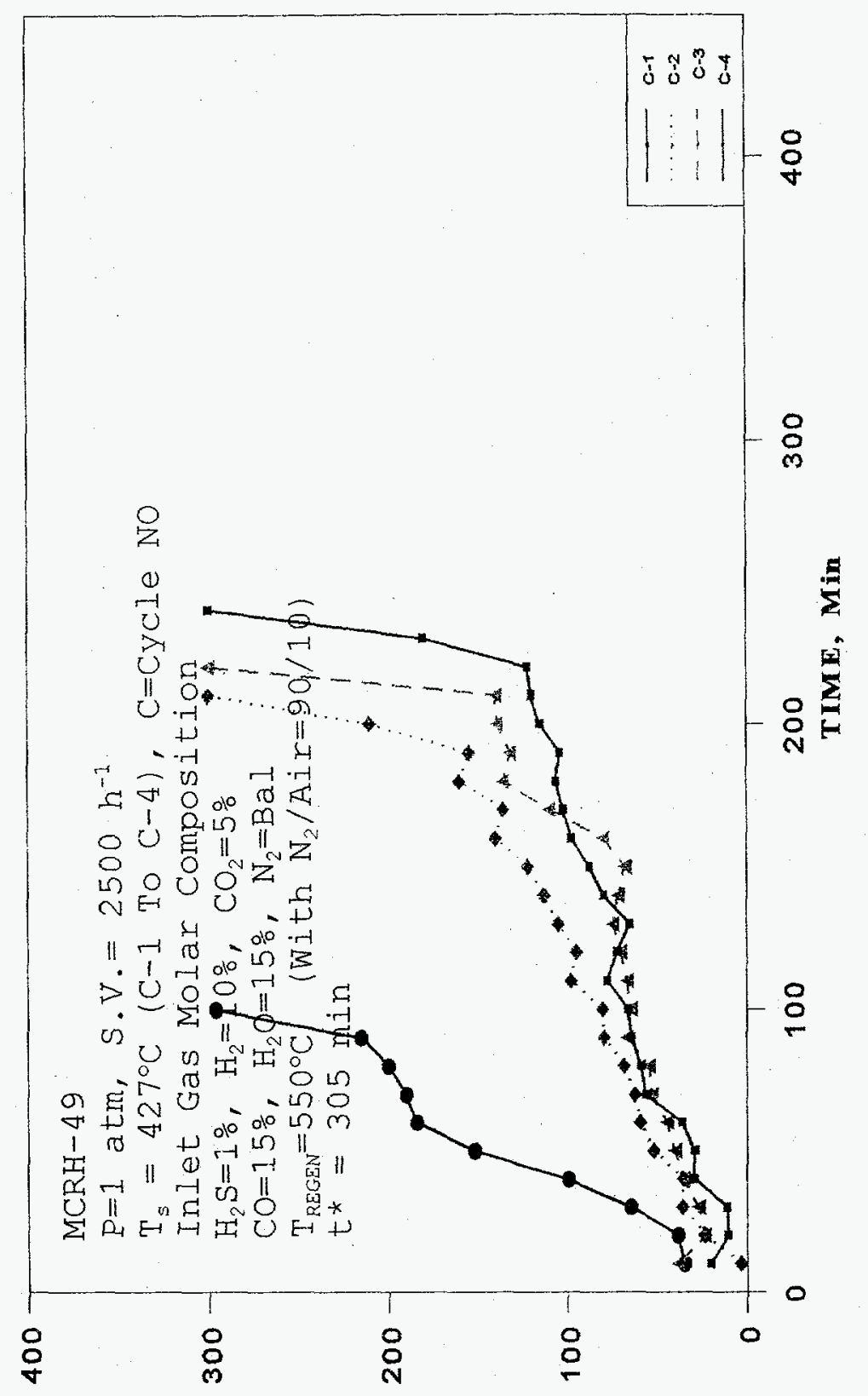

(udd) $S^{2} \mathrm{H}$ 山'HTL 